\title{
Sistem Klasifikasi Musik Gamelan Angklung Bali Terhadap Suasana Hati Menggunakan Algoritma K-Nearest Neighbor Berbasis Algoritma Genetika
}

\author{
Tria Hikmah Fratiwi ${ }^{1}$, Made Sudarma ${ }^{2}$, Nyoman Pramaita ${ }^{3}$ \\ [Submission: 040-06-2021, Accepted:13-08-2021]
}

\begin{abstract}
Balinese gamelan angklung music through its sound waves can interfere the waves of human's thought to decrease brain's wave frequency. The aim is to affect the psychological condition in term of mood so it will lead to positive stress level with either low or high energy. Music with positive stress level and low energy level is categorized as contentment. Positive stress level music and high energy level is categorized as exuberance. MIR (Music Information Retrieval) is a part of Data Mining which digging information about music's data. One of them is the mood's classification which is interpreted by chunks of music data. This research designs and builds the classification system to detect the Balinese gamelan angklung instrumental music's mood using K-NN algorithm and K-NN based Genetic Algorithm. K-NN is able to overcome the classification problem well. However, behind its excellence, the very sensitive $k$ value setting becomes a weakness. Applying Genetic Algorithm on the K-NN classification system optimizes the optimal $k$ value's determination. Based on the same training and testing data set, $\mathrm{K}-\mathrm{NN}$ gives $87,84 \%(k=14)$ as the highest accuracy percentage, while K-NN based Genetic Algorithm gives $89,19 \%(k=3)$ as the highest accuracy percentage.
\end{abstract}

Intisari-Musik gamelan angklung Bali lewat gelombang bunyi yang dihasilkannya mampu menginterferensi gelombang pikiran manusia untuk menurunkan frekuensi gelombang yang dipancarkan oleh otak. Tujuannya untuk mempengaruhi kondisi psikologi yang berkaitan dengan suasana hati agar mengarah pada tingkat stress positif dengan tingkat energi rendah maupun tinggi. Musik dengan tingkat stress positif dan tingkat energi rendah masuk ke dalam kategori suasana hati tenang atau contentment, jika tingkat stress positif dan tingkat energi tinggi masuk ke dalam kategori suasana hati senang atau exuberance. MIR (Music Information Retrieval) adalah bagian dari Data Mining yang menggali informasi mengenai data musik, salah satunya yaitu klasifikasi suasana hati yang diinterpretasikan oleh potongan data musik. Penelitian ini merancang dan membangun sistem klasifikasi untuk mendeteksi suasana hati musik gamelan angklung Bali menggunakan algoritma K-NN dan K-NN berbasis Algoritma Genetika. K-NN dapat mengatasi masalah klasifikasi dengan baik, namun dibalik keunggulannya,

${ }^{1}$ Mahasiswa, Magister Teknik Elektro Universitas Udayana, Gedung Pascasarjana Universitas Udayana Jl. PB Sudirman Denpasar-Bali, Kode Pos: 80232 (tlp/fax: 0361-239599; e-mail: tria.hf@gmail.com)

2, 3 Dosen, Magister Teknik Elektro Universitas Udayana, Gedung Pascasarjana Universitas Udayana Jl. PB Sudirman Denpasar-Bali, Kode Pos: 80232 (telp/fax: 0361-239599; e-mail: imasudarma@gmail.com,pramaita@ee.unud.ac.id)

Tria Hikmah Fratiwi: Sistem Klasifikasi Musik Gamelan ... pengaturan nilai $k$ yang sangat sensitif menjadi sebuah kelemahan. Menerapkan operasi genetika oleh Algoritma Genetika pada sistem klasifikasi K-NN berhasil mengoptimasi penentuan nilai $k$ optimal, serta memperbaiki hasil akurasi klasifikasi. Berdasarkan dataset training dan dataset testing yang sama, K-NN memberikan persentase akurasi tertinggi sebesar $87,84 \% \quad(k=14)$, sedangkan K-NN berbasis Algoritma Genetika memberikan persentase akurasi tertinggi sebesar $89,19 \%(k=3)$.

Kata Kunci-K-NN, Algoritma Genetika, suasana hati, gamelan angklung Bali.

\section{PENDAHULUAN}

Gamelan angklung Bali adalah instrumen musik yang berfungsi sebagai sarana ritual keagamaan, pemberi isyarat atau pertanda adanya suatu upacara, dan pembentuk suasana, baik penambah kekhidmatan maupun pembangkit semangat. Musik gamelan angklung Bali mampu memicu perubahan suasana hati secara alami melalui gelombang bunyi yang menginterferensi gelombang pikiran manusia. Ketika dilaksanakannya sebuah ritual atau acara, sejumlah orang hadir membawa permasalahan masing-masing di dalam pikirannya, sehingga menyebabkan hiruk-pikuk yang dapat menurunkan nilai dari ritual atau acara. Kehadiran musik gamelan dapat mengatur kekacauan tersebut dengan cara mengalihkan pikiran manusia, sehingga menurunkan frekuensi gelombang yang dipancarkan oleh otak manusia [1]. Perlunya menilai suasana hati yang mampu diinterpretasikan oleh musik gamelan angklung Bali menjadi penting agar terhindar dari kesalahan pemilihan musik yang kurang sesuai dengan suasana yang ingin diciptakan untuk meningkatkan keberhasilan sebuah ritual atau acara.

Model suasana hati yang diadaptasi dari kata sifat untuk menghindari keambiguan dapat dijadikan acuan dalam melakukan penilaian interpretasi suasana hati musik. Salah satunya model suasana hati yang dikembangkan oleh Robert Thayer yang mengkombinasikan dua faktor dimensi yaitu, stress terdiri dari positif dan negatif, serta energi terdiri dari aktif dan pasif. Dari kedua dimensi tersebut, terbentuk empat kuadran yang masing-masing menyatakan sebuah kata sifat dari suatu keadaan emosi, antara lain exuberance, anxious, depression, dan contentment. Musik gamelan angklung Bali jika ditelaah dari karakter permainan bunyinya dan fungsinya, tergolong berada pada kuadaran pertama yang menyatakan suasana hati exuberance atau senang, dan ke-empat yang menyatakan suasana hati contentment atau tenang. 
Mencari kecenderungan suasana hati pada suatu data musik merupakan bagian dari penelitian MIR (Music Information Retrieval). Melalui teknologi data mining yang menerapkan algoritma klasifikasi, MIR menggali dan mendeteksi informasi sekelompok data musik terhadap suasana hati berdasarkan kemiripannya. Data musik yang akan dikelompokkan pada penelitian ini adalah hasil segmentasi tabuh gamelan angklung Bali berdurasi 20 detik dengan format .wav yang telah diberikan label suasana hati. Penentuan durasi berdasarkan hasil pengukuran rata-rata durasi minimum dari sejumlah potongan data representatif pada tiap bagian tabuh gamelan angklung Bali. Hasil dari segmentasi data dibagi untuk keperluan data latih dan data uji pada tahap pengolahan data.

Pengolahan data terdiri dari dua tahapan, ekstraksi fitur dan klasifikasi. Tahap ekstraksi fitur diawali dengan mentransformasikan data dari domain waktu ke domain frekuensi menggunakan metode FFT (Fast Fourier Transform). FFT memiliki kelebihan performansi yang cepat dan efisien dalam menghitung transformasi fourier diskrit sehingga sesuai untuk sinyal bersifat kontinyu seperti sinyal suara. Dalam ekstraksi fitur dilakukan analisa beberapa spektral dari sinyal suara untuk mendapatkan karakteristik yang tepat, diantaranya centroid, skewness, rolloff, kurtosis, spread, dan flatness. Analisis spektral merupakan tahap terpenting dalam penelitian MIR karena akan menjadi tolak ukur yang mempengaruhi hasil dari pengklasifikasian data di tahap selanjutnya [2].

Tahap klasifikasi menggunakan algoritma data mining $\mathrm{K}$ NN (K-Nearest Neighbor) yang cocok diimplementasikan pada set data nonlinear seperti data musik, karena garis keputusan kelas yang dihasilkan bersifat fleksibel. K-NN mengklasifikasikan obyek baru melalui nilai $k$ terdekat dengan tetangganya berdasarkan atribut dan sampel data latih. Dibalik keunggulannya, pengaturan nilai $k$ yang sangat sensitif menjadi sebuah kelemahan dalam K-NN. Mengaplikasikan GA (Genetic Algorithm) pada K-NN dapat memecahkan masalah pengaturan nilai $k$ sekaligus memaksimalkan kinerja sistem klasifikasi. GA mengadaptasi operasi genetika untuk menemukan solusi optimal dengan cara reproduksi untuk mendapatkan generasi baru terbaik melalui tiga fase utama yaitu, fitness selection, crossover, dan mutase. Penerapan GA pada sistem klasifikasi K-NN telah dilakukan pada penelitian sebelumnya [3][4]. Kedua penelitian tersebut berhasil mengoptimasi pemilihan nilai $k$ sehingga menghasilkan persentase akurasi yang lebih tinggi dibandingkan dengan K-NN tanpa GA. Bahkan pada penelitian tersebut membuktikan bahwa K-NN dengan GA lebih unggul dari pada metode klasifikasi lainnya.

\section{LANDASAN TEORI}

Berikut akan dijelaskan mengenai teori pendukung yang menjadi landasan penelitian ini, antara lain:

\section{A. Gamelan Angklung Bali}

Angklung adalah ansambel gamelan Bali berlaras slendro. Ketika upacara pitra yadnya, angklung bisa memainkan gending-gending pategak untuk menambah kekhidmatan upacara atau gending gilak untuk mengiringi prosesi pemberangkatan jenazah dari rumah duka menuju ke tempat peristirahatan terakhir [5]. Berdasarkan konteks fungsi penggunaannya, serta materi tabuh yang dibawakan, gamelan angklung Bali dapat dibedakan menjadi dua. Angklung klasik yang dimainkan untuk mengiringi upacara (tanpa tari-tarian), dan angklung kebyar yang dimainkan untuk mengiringi pementasan tari dan juga drama. Pada awalnya gamelan angklung Bali digunakan sebagai pelengkap pelaksanaan ritual, namun dewasa ini berkembang pada fungsi sosial yang lebih luas, yakni sebagai seni pertunjukan [6].

Tabuh gamelan angklung Bali dibagi menjadi 3 bagian, pengawit, pengawak, dan pengecet. Pengawit memberikan pengantar atau perkenalan suasana, pengawak merupakan inti, dan pengecet merupakan kepadatan dari pengawak dengan tempo yang dipercepat. Tabuh dalam gamelan angklung Bali mengarah pada sebuah tema yang berlandas pada pembentukan gagasan atau ide dari suasana hati yang ingin dicapai. Suasana hati yang diiterpretasikan oleh tabuh gamelan angklung Bali mengacu pada permainan nada-nada cepat, lambat, keras, lembut, berat, dan ringan. Nada yang terbatas membentuk teknik permainan sederhana, sehingga menghasilkan gendingan yang juga sederhana. Kesederhanaan tersebut menghasilkan musik atau tabuh yang melankolis, sehingga mampu menstimulus munculnya suasana tenang. Akan tetapi pada angklung kebyar dilakukan adaptasi teknik permainan gong kebyar yang cenderung rumit. Sehingga menghasilkan tema lain dengan interpretasi suasana hati yang beragam [7].

\section{B. MIR (Music Information Retrieval)}

MIR (Music Information Retrieval) merupakan sebuah bidang ilmu yang fokus pada sains dan musik. MIR tertarik pada informasi yang bisa diambil dan diolah dari data set musik melaui metode-metode sains komputer. Permasalahan utama dalam penelitian MIR adalah klasifikasi, karena berdasarkan data yang tercatat pada MIREX (Music Information Retrieval Evaluation eXchage) sejak tahun 2004, sebagian besar peneliti MIR menitikberatkan pada pengklasifikasian musik, antara lain klasifikasi genre dan mood, identifikasi artis, pengenalan instrumen, dan anotasi musik [8]. Klasifikasi berperan penting terhadap penandaan sebuah label dalam kategori data musik. Semisal pemberian label pada kategori suasana hati atau mood yang terdeteksi dari data musik, apakah senang, sedih, marah, atau tenang.

\section{Suasana Hati pada Musik}

Musik dapat membantu menutupi kebisingan yang samar untuk menciptakan lingkungan mendukung yang berkesinambungan [9]. Musik mampu mengekspresikan kekuatan dan kelembutan dari suatu keadaan emosi. Dari stimulus musik yang sama mampu menggambarkan pengalaman emosi yang sama, yang membedakan ialah penggunaan kata untuk mendeskripsikannya [10]. Suasana hati atau mood adalah keadaan emosi yang relatif tahan lama dan cenderung bersifat permanen. Suasana hati atau mood berbeda dengan emosi yang sederhana dimana emosi lebih bersifat temporal atau cepat berlalu dari ingatan karena kurang spesifik dan kurang intens. Mengadaptasi model suasana hati untuk mendefinisikan emosi individu menjadi solusi bagi masalah variasi persepsi suasana hati pada musik. 
Model suasana hati usulan Robert Thayer salah satu yang cukup populer digunakan. Thayer melakukan pendekatan dua dimensi yang menawarkan cara sederhana yang efektif untuk mendefinisikan suasana hati. Model Thayer mendefinisikan suasana hati bergantung pada dua faktor, antara lain stress (positif dan negatif) dan energi (aktif dan pasif) yang dirancang dalam sumbu dua dimensi sehingga membentuk empat kuadran berbeda yaitu : exuberance atau kegembiraan mewakili jenis suasana hati musik yang mengacu pada stress positif dan energi tinggi, anxious atau kecemasan mewakili jenis suasana hati musik yang mengacu pada stress negatif dan energi tinggi, depression atau kesedihan mewakili jenis suasana hati musik yang mengacu pada stress negatif dan energi rendah, contentment atau ketenangan mewakili jenis suasana hati musik yang mengacu pada stress positif dan energi rendah [11].

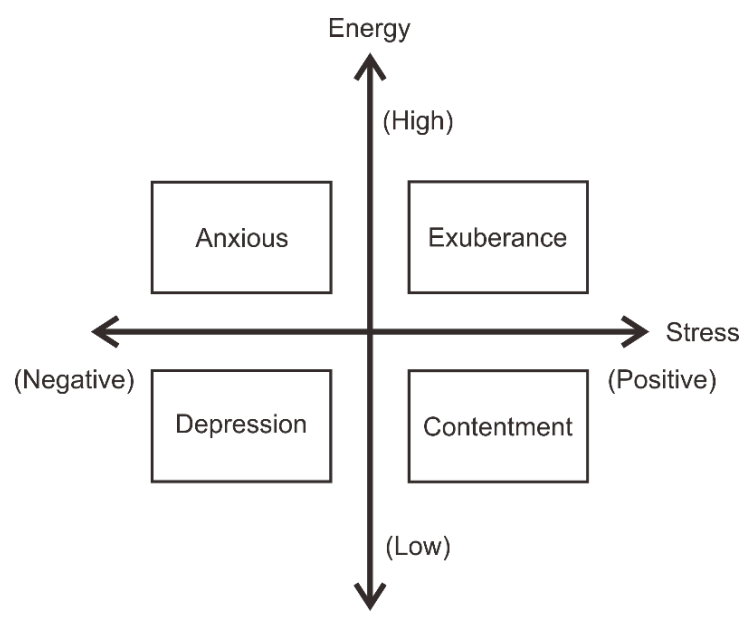

Gambar 1: Dimensi emosi model Robert Thayer.

\section{Label Suasana Hati Musik Gamelan Angklung Bali}

Pelabelan suasana hati musik gamelan angklung Bali merupakan proses pemberian tanda suasana hati yang dinterpretasikan oleh musik itu sendiri. Standar penilaian suasana hati dari sebuah tabuh gamelan Bali dipengaruhi oleh faktor ritme atau irama yang digagas dari sebuah tema yang hendak dicapai oleh komposer. Ritme adalah pola nada berulang yang terbentuk dari suara dan diam, dengan demikian tempo dan ketukan memiliki pengaruh dalam penyusunannya. Ritme dinamis membuat gerak menjadi lebih aktif mengikuti ketukan, ritme melankolis menjadikan badan lebih tenang, sehingga membuat tubuh menghayati gerak. Dengan demikian pada gamelan angklung Bali, tabuh yang keras akan membangunkan gairah, sedangkan tabuh yang melankolis akan melunakkan perasaan [7].

Secara filosofis vibrasi gelombang bunyi gamelan Bali dipercaya sebagai manifestasi mantram atau suara puja yang ditujukan kepada Ista Dewata (perwujudan Tuhan dalam berbagai wujud-Nya) sebagai konsep keseimbangan mikrokosmos, makrokosmos, dan metakosmos. Gelombang bunyi yang dihasilkan dari permainan instrumen gamelan Bali dapat menurunkan frekuensi gelombang $\beta$ (aktifitas mental terjaga penuh) yang dipancarkan oleh otak manusia menjadi gelombang $\alpha$ (kesadaran yang rileks) yang niscaya akan Tria Hikmah Fratiwi: Sistem Klasifikasi Musik Gamelan ... menuntun pikiran menuju Tuhan, yang dalam psikologis dapat diartikan sebagai dorongan yang mengarah pada pemikiran positif. Konsep tersebut sejalan dengan fungsi utama bunyi gamelan angklung Bali pada upacara pitra yadnya sebagai sarana untuk menciptakan kondisi psikologis agar yang ditinggalkan tidak terlalu berduka [1].

Standar penilaian yang digunakan pada penelitian ini merujuk pada dua parameter, yaitu ritme dinamis dan ritme melankolis yang diadaptasi sebagai tingkatan energi pada model suasana hati Robert Thayer, sedangkan tingkatan stress secara keseluruahan dianggap positif dengan mengacu pada esensi filosofis dan esensi psikologis dari fungsi tabuh gamelan angklung Bali yang dipercaya oleh umat hindu Bali. Sehingga akan terbentuk dua kelompok suasana hati yakni exuberances atau senang, serta contentment atau tenang yang dikerjakan pada penelitian ini.

TABEL I

STANDAR PEMBERIAN LABEL

\begin{tabular}{|c|c|c|c|c|}
\hline Nama & Ritme & Stress & Energi & $\begin{array}{c}\text { Suasana } \\
\text { Hati }\end{array}$ \\
\hline Musik 1 & Melankolis & Positif & Rendah & Contentment \\
\hline Musik 2 & Dinamis & Positif & Tinggi & Exuberance \\
\hline Musik 3 & Melankolis & Positif & Rendah & Contentment \\
\hline Musik 4 & Dinamis & Positif & Tinggi & Exuberance \\
\hline
\end{tabular}

\section{E. FFT (Fast Fourier Transform)}

Fast Fourier Transform (FFT) adalah metode untuk mentransformasikan sinyal dalam domain waktu menjadi domain frekuensi. Sinyal dalam domain frekuensi diperlukan untuk menganalisa sinyal yang mengandung beberapa frekuensi yang bercampur, contohnya seperti sinyal suara pada musik gamelan angklung Bali. Metode FFT sangat efisien untuk menghitung koefisien dari Fourier diskrit ke suatu finite sekuen dari data yang kompleks. Banyak sinyalsinyal dalam sistem komunikasi yang bersifat continue, pada kasus sinyal continue seperti sinyal suara dapat menggunakan transformasi fourier [12]. Persamaan FFT didefinisikan sebagai berikut:

$$
s(f)=\int_{-\infty}^{\infty} s(t) e^{-j 2 \pi f t} d t
$$

Dimana $s(f)$ adalah sinyal dalam domain frekuensi, $s(l)$ adalah sinyal dalam domain waktu, dan $e^{-j 2 \pi f t}$ adalah konstanta dari nilai sebuah sinyal, $f$ adalah frekuensi dan $t$ adalah waktu.

\section{F. Feature Extraction}

Feature extraction atau ekstraksi fitur merupakan tahapan penting dalam penelitian klasifikasi suasana hati data musik. Proses ekstraksi fitur dilakukan dengan cara mengambil ciriciri dari karakteristik sebuah data input, sehingga menghasilkan nilai fitur yang kemudian diolah untuk menentukan kelas atau kelompoknya. Terdapat dua teknik ekstraksi fitur audio yakni analisis temporal dan analisis spektral. Teknik analisis temporal memanfaatkan bentuk gelombang dari sinyal audio untuk melakukan analisis,

p-ISSN:1693 - 2951; e-ISSN: 2503-2372 
sedangkan analisis spektral memanfaatkan representasi spektral dari sinyal audio untuk melakukan analisis.

Penelitian ini menerapkan teknik analisis spektral yang terdiri dari beberapa metode ekstraksi fitur. Metode ekstraksi fitur yang pertama yakni diperoleh berdasarkan pada properti statistik (statistical property), melalui panjang blok sebuah sinyal audio, serta tingkatan nada yang diperoleh dari proses ekstraksi. Dalam hal ini digunakan spectral analysis skewness dan kurtosis. Metode kedua, fitur dari audio didapatkan dari bentuk spektral (spectral shape), yang diketahui melalui timbre (warna suara), pitch (tinggi atau rendah sebuah nada) dan loudness (kuat atau lemahnya suara). Untuk memperoleh nilai fitur audio pada spectral shape ini digunakan spectral analysis centroid, rolloff, dan spread. Metode ketiga, fitur audio didapat melalui properti sinyal (signal properties), dimana fitur audio yang dianalisis didasari oleh nada di sepanjang sinyal audio, hal ini memvisualkan keharmonisan dalam musik. Untuk mendapatkan nilai fitur audio berdasarkan signal properties digunakan spectral analysis flatness [2][13].

\section{G. $K$-NN (K-Nearest Neighbor)}

Algoritma K-Nearest Neighbor atau yang biasa disebut K$\mathrm{NN}$ adalah sebuah metode yang bersifat supervised, dimana hasil dari query instance yang baru diklasifikasikan berdasarkan mayoritas keanggotaan kategori pada memori data pembelajaran [14]. K-NN melakukan klasifikasi terhadap objek berdasarkan data pelatihan yang jarak ketetanggaannya (k) paling dekat dengan objek tersebut. Jarak terdekat atau terjauh suatu ketetanggaan dihitung berdasarkan jarak euclidean melalui persamaan (2) yang diuraikan sebagai berikut:

$$
\begin{aligned}
& d=\sqrt{\left(a_{1}-b_{1}\right)^{2}+\left(a_{2}-b_{2}\right)^{2}+\cdots+\left(a_{n}-b_{n}\right)^{2}} \\
& d=\sum_{l=1}^{n_{1}}\left(a_{i}-b_{i}\right)^{2}
\end{aligned}
$$

Klasifikasi K-NN memilah $k$-buah tetangga dengan jarak terdekat dan memilih kelas dengan $k_{i}$ terbanyak (mayoritas) pada kelas $\omega_{i}$. Langkah-langkah K-NN dalam melakukan klasifikasi adalah sebagai berikut:

1. Mengenali $k$-buah tetangga terdekat dari sampel $x$ pada sekumpulan vektor data latih yang memiliki $N$ titik data secara keseluruhan.

2. Mengidentifikasikan jumlah vektor $k_{i}$ pada kelas $\omega_{i}$, $i=1,2, \ldots, m$ dengan $\Sigma_{i} k_{i}=k$, dari $k$-buah tetangga terdekat tersebut.

3. Memasukkan $x$ pada kelas $\omega_{i}$ dengan nilai $k_{i}$ maksimum.

4. Jika terdapat kondisi dimana dua atau lebih kelas $\omega_{i}$ yang memiliki $E$ tetangga terdekat, hal itu disebut sebagai kondisi seimbang yang menandai terjadinya konflik, namun dapat diatasi menggunakan strategi pemecahan konflik.

5. Strategi pemecahan konflik dilakukan dengan cara memetakan masing-masing kelas yang terlibat dalam konflik. Tentukan jarak di antara $x$ dengan kelas $\omega_{i}$ berdasarkan $E$ tetangga terdekat yang ditemukan pada kelas $\omega_{l}$.
6. Jika pola pelatihan ke- $m$ dari kelas $\omega_{i}$ yang terlibat dalam konflik ditunjukkan dengan $y^{i m}=\left\{y_{1}^{i m}, \ldots, y_{N}^{i m}\right\}$ maka jarak antara $x$ dengan kelas $\omega_{i}$ adalah:

$d_{i}=\frac{1}{E} \sum_{f=1}^{N}\left|\left(x_{j}-y_{j}^{i m}\right)\right|$

7. Masukkan $x$ ke dalam kelas, yaitu $x \in \omega C$, jika $d C<d_{i}$ untuk $i_{i} C \subset[1, \ldots, M]$ dan $i \neq C$.

Salah satu yang perlu diperhatikan untuk menggunakan algoritma K-NN secara efektif, sehingga dapat memberikan hasil pengklasifikasian dengan akurasi yang lebih baik adalah memilih jumlah $k$ yang paling tepat agar error rate bisa diperkecil [15].

\section{H. GA (Genetic Algorithm)}

GA (Genetic Algorithm) adalah sebuah algoritma pencarian yang meniru mekanisme dari proses genetika alam. Algoritma ini diawali oleh kumpulan solusi yang disebut sebagai populasi. Solusi-solusi dari sebuah populasi dipilih dan digunakan untuk membentuk populasi yang baru dengan harapan, bahwa populasi yang baru dibentuk tersebut akan lebih baik daripada yang lama. Populasi dipilih untuk membentuk populasi baru yang diseleksi berdasarkan nilai fitness masing-masing individu [16]. Berikut dijabarkan langkah-langkah GA yang sering diterapkan [17].

1. Teknik encoding decoding bertujuan untuk mengkodekan nilai gen-gen pada kromosom pembentuk individu. Ada tiga pengkodean yang sering digunakan, yaitu pengkodean bilangan real, diskrit desimal, dan biner.

2. Menentukan jumlah individu dalam populasi awal yang akan dibangkitkan secara acak.

3. Nilai fitness didefinisikan sebagai nilai dari fungsi tujuan. Tujuan dari GA adalah memaksimalkan nilai fitness. Jika mencari nilai maksimal, maka nilai fitness adalah nilai dari fungsi itu sendiri. Tetapi, jika yang diperlukan nilai minimal, maka nilai fitness adalah invers dari nilai fungsi itu sendiri. Persamaan (4) nilai fungsi fitness sebagai berikut:

Fitness $=C-f(x)$ atau Fitness $=\frac{C}{f(x) \mathrm{\epsilon}}$

$C$ adalah konstanta dan $\in$ adalah bilangan kecil yang ditentukan untuk menghindari agar tidak terjadi pembagian oleh nol, sedangkan $x$ adalah individu.

4. Elitisme adalah prosedur untuk menduplikat individu yang mempunyai nilai fitness tertinggi sebanyak satu (jika individu dalam suatu populasi berjumlah ganjil) atau dua (jika individu dalam suatu populasi berjumlah genap). Hal tersebut dilakukan agar individu terbaik tersebut tidak mengalami kerusakan atau penurunan nilai fitness selama proses pindah silang maupun mutasi.

5. Seleksi adalah proses pemilihan dua buah individu yang akan dijadikan parent atau orang tua pada proses reproduksi dalam rangka pembentukan individu baru dengan kualitas terbaik. Metode seleksi yang sering digunakan adalah Roulette Wheel. 
Majalah Ilmiah Teknologi Elektro, Vol. 20, No.2, Jali-Desember 2021

DOI: https://doi.org/10.24843/MITE.2021.v20i02.P10

6. Crossover dapat dioperasikan hanya jika $r<$ prob. $r$ adalah sebuah bilangan random dalam interval [ $\left[\begin{array}{ll}0 & 1\end{array}\right]$ yang dibangkitkan nilainya, dan prob adalah probabilitas tertentu. Biasanya nilai prob diatur mendekati 1. Cara paling sederhana untuk melakukan pindah silang adalah pindah silang satu titik potong [18]. Posisi titik potong dilakukan secara random.

7. Mutasi dilakukan pada semua gen kromosom pembentuk individu, jika bilangan random yang dibangkitkan lebih kecil dan probabilitas mutasi $p$ yang ditentukan. Biasanya $p$ diatur $=1 / N$, dimana $N$ adalah jumlah gen dalam individu. Untuk kode biner, mutasi dilakukan dengan cara membalik nilai bit 0 menjadi bit 1 , sebaliknya bit 1 diubah menjadi bit 0 .

8. Penggantian populasi (generational replacement) bertujuan untuk mengganti semua individu awal dalam satu generasi oleh temporal individu hasil reproduksi atau regenerasi. Setelah dilakukan penggantian populasi, maka populasi baru disebut sebagai generasi baru dan siap diproses lagi hingga generasi ke- $n$.

\section{Pengujian Akurasi}

Penelitian ini menggunakan teknik pengujian accuracy (akurasi) untuk mengetahui sebaik apa sistem melakukan klasifikasi. Akurasi diartikan sebagai tingkat kedekatan antara nilai prediksi dengan nilai aktual. Menghitung akurasi klasifikasi dapat dirumuskan sebagai berikut [19]:

$$
\text { Akurosi }=\frac{\text { Jumlah data tes benar }}{\text { Jumlah seluruh data tes }} \times 100 \%
$$

\section{Metodelogi PENELITIAN}

\section{A. Prapengolahan Data Musik}

Penelitian ini menggunakan data yang didapatkan dari beberapa kaset pita dan $c d$ musik gamelan angklung Bali, serta beberapa platform musik digital seperti youtube dan sebagainya. Data musik yang terkumpul, masing-masing bagiannya diberikan label suasana hati berdasarkan standar yang telah ditetapkan oleh pakar musik gamelan Bali. Kemudian dilakukan segmentasi data musik menggunakan aplikasi edit suara Adobe Audition untuk memotong bagian data musik yang dianggap paling merepresentatifkan mood atau suasana hati. Penelitian ini mensegmentasikan data musik dengan mengambil bagian yang paling representatif dari pengawit, pengawak, dan pengecet dalam kesatuan tabuh dengan durasi 20 detik berdasarkan hasil mengukur durasi minimum dari keseluruhan data representatif dengan format data mono .wav. Format mono tersebut untuk menyesuaikan dengan sistem kerja FFT yang hanya bisa memproses satu saluran.

Sebelum dilanjutkan ke proses ekstraksi FFT, data set dievaluasi labelnya terlebih dahulu oleh tiga orang pakar musik gamelan Bali untuk mencegah terjadinya kesalahan

Tria Hikmah Fratiwi: Sistem Klasifikasi Musik Gamelan ... penilaian suasana hati. Evaluasi dilakukan dengan memperdengarkan data set pada pakar musik gamelan Bali dan meminta untuk memilih suasana hati apa yang dirasakan ketika mendengar. Proses evaluasi menghasilkan data set label yang dibagi menjadi dua bagian untuk kepentingan data latih dan data uji dengan perbandingan $70 \%$ banding $30 \%$.

\section{B. Klasifikasi Mood Musik dengan K-NN Berbasis GA}

Pertama, GA akan mulai mengoperasikan fase-fase genetikanya untuk mengoptimalkan pencarian nilai $k$, sebelum K-NN melakukan klasifikasi. GA berperan sebagai metode optimasi melalui pembentukan populasi baru yang dianggap lebih baik karena dihasilkan melalui reproduksi antara dua individu terbaik di dalam populasi lama. Populasi baru terbentuk setelah melewati beberapa tahapan seperti yang dijelaskan pada Gambar 2.

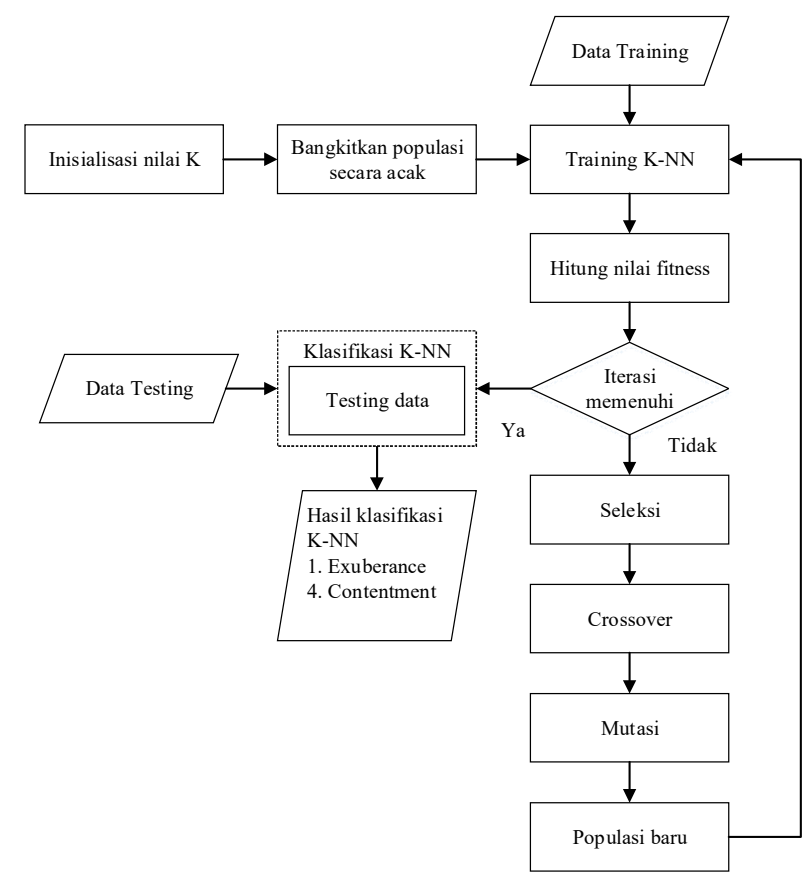

Gambar 2: Diagram alir proses klasifikasi K-NN berbasis GA.

Tahapan-tahapan yang bekerja pada proses GA dijelaskan sebagai berikut:

1. Tentukan data latih atau data training.

2. Inisialisasi nilai $\mathrm{k}$ sebagai target optimasi solusi (kromosom) yang didasari oleh batasan nilai $\mathrm{k}$ pada sistem klasifikasi K-NN dalam penelitian ini yakni 1 sampai 15, sehingga inisialisasi nilai $\mathrm{k}$ berjumlah 15 . Batasan tersebut menghasilkan panjang gen sebanyak 4 (dalam bilangan biner) pada masing-masing kromosom.

3. Tentukan jumlah populasi yang akan dibangkitkan secara acak dengan ketentuan bahwa jumlah populasi tidak melebihi jumlah inisialisasi target solusi.

4. Hitung nilai fitness menggunakan nilai akurasi, yang mana nilai akurasi tertinggi adalah nilai fitness terbaik.

5. Proses seleksi menggunakan metode roulette-wheel, yang sebelumnya telah melewati tahap elitisme (mengkopi kromosom dengan nilai fitness terbaik sebanyak 1 jika

$$
\text { p-ISSN:1693 - 2951; e-ISSN: 2503-2372 }
$$


jumlah populasi ganjil, atau 2 jika jumlah populasi genap) untuk menjaga kualitas populasi.

6. Proses crossover dilakukan dari dua kromosom induk yang telah terpilih pada proses seleksi. Angka probabilitas yang digunakan sebesar 0,8 karena diharapkan operasi ini memiliki keberhasilan yang tinggi.

7. Proses mutasi pada kromosom (offspring) hasil perpindahan silang (crossover) menggunakan angka probabilitas sebesar 0,1 . Penggunaan angka probabilitas sekecil-kecilnya untuk memperkecil kemungkinan operasi ini.

8. Populasi baru akan terbentuk atau GA akan terus melakukan operasi regenerasi hingga mencapai iterasi yang ditentukan oleh jumlah generasi maksimal.

9. Didapatkan individu baru atau nilai $k$ terbaik yang optimal.

GA bekerja pada proses pelatihan data atau training data, yang mana memberikan output berupa nilai $k$ optimal. Nilai $k$ tersebut akan dilanjutkan ke operasi klasifikasi oleh algoritma K-NN. Data uji yang dimasukkan ke dalam sistem akan dievaluasi kedekatannya berdasarkan nilai $k$ hasil operasi optimasi oleh GA menggunakan rumus euclidean distance. Data training dengan jarak terdekat dengan data uji serta menjadi mayoritas dalam keanggotaan sejumlah $k$ akan dijadikan acuan untuk menentukan identitas atau label dari data uji.

Jika terjadi konflik, maka pada proses terakhir akan dilakukan penghitungan jarak antara tiap kelas yang terjadi konflik, kemudian menentukan kelas atau kategori dengan jarak rata-rata yang paling kecil. Hasil akhir dari proses klasifikasi K-NN ini adalah label salah satu kategori mood dari dua kategori yaitu: contentment dan exuberance, serta waktu proses klasifikasi. Nilai $k$ optimal didapatkan secara otomatis melalui operasi genetika oleh GA.

\section{HASIL DAN PEMBAHASAN}

\section{A. Antarmuka Sistem}

Klasifikasi diawali dengan proses training menggunakan dataset training yang telah diinput sebelumnya untuk menentukan nilai $k$ optimal. Nilai $k$ optimal dipengaruhi oleh tiga parameter yaitu, jumlah inisialisasi nilai $k$, jumlah populasi, dan jumlah generasi maksimal atau gen max.

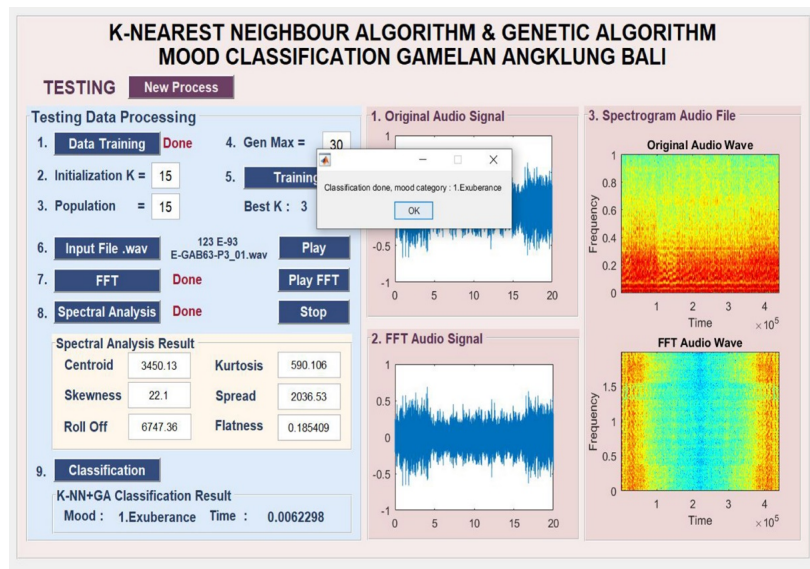

Gambar 3: Antarmuka sistem klasifikasi K-NN berbasis GA.
Antarmuka klasifikasi K-NN berbasis GA memiliki tombol primer dan tombol sekunder sebagai navigasi yang akan menterjemahkan perintah pengguna pada sistem. Tombol primer antara lain, tombol New Process untuk memuat ulang halaman, tombol Data Training untuk memasukkan file database pelatihan sebagai acuan proses penentuan nilai $k$ optimal serta klasifikasi, tombol Training untuk memulai proses regenerasi dalam upaya mencari $k$ optimal, tombol Input File .wav untuk memuat file data uji dengan format .wav, tombol FFT untuk mentransformasikan sinyal audio input dari domain waktu ke domain frekuensi, tombol Spectral Analysis untuk mengekstraksi fitur-fitur yang dimiliki oleh file audio yang telah ditransformasikan oleh FFT (nilai keluarannya akan dimunculkan pada textbox sesuai dengan jenis fiturnya), serta tombol Classification untuk memulai proses klasifikasi yang menghasilkan label suasana hati dari file audio input.

Tombol sekunder pada antarmuka ini terdiri dari tombol Play untuk mendengarkan audio input, tombol Play FFT untuk mendengarkan audio hasil transformasi oleh FFT, dan tombol Stop untuk berhenti mendengarkan audio. Tombol Play dan tombol Play FFT dapat dijadikan pembanding kualitas audio sebelum dan sesudah proses FFT. Sedangkan untuk membandingkan representasi dari bentuk sinyal dan spektrumnya dapat dilihat pada panel Original Audio Signal, FFT Audio Signal, dan Spectrogram Audio File.

\section{B. Hasil dan Analisa Sistem}

Percobaan untuk menemukan nilai $k$ optimal oleh GA dilakukan sebanyak sembilan kali dengan kombinasi jumlah populasi dan generasi maksimal yang bervariasi. Penentuan jumlah populasi dan generasi maksimal memiliki ketentuan, untuk populasi jumlahnya tidak lebih dari 15 karena disesuaikan dengan nilai $k$ yang digunakan pada penelitian ini yaitu 1 sampai 15 (inisialisasi $k=15$ ), sedangkan jumlah generasi maksimal dapat ditentukan secara random, namun perlu diketahui bahwa semakin besar jumlah generasi maksimal, maka semakin lama waktu komputasinya. Jumlah generasi maksimal berkaitan dengan perulangan yang dilakukan oleh GA dalam rangka memenuhi jumlah populasi baru pada proses regenerasi.

TABEL III

HASIL REGENERASI OLEH GA UNTUK MENCARI NILAI K OPTIMAL

\begin{tabular}{|c|c|c|c|}
\hline Generasi & \multicolumn{3}{|c|}{ Populasi } \\
\cline { 2 - 4 } Maksimal & $\mathbf{5}$ & $\mathbf{1 0}$ & $\mathbf{1 5}$ \\
\hline $\mathbf{1 0}$ & 3 & 3 & 3 \\
\hline $\mathbf{2 0}$ & 3 & 3 & 3 \\
\hline $\mathbf{3 0}$ & 3 & 3 & 3 \\
\hline
\end{tabular}

Persentase keakuratan hasil klasifikasi oleh K-NN berbasis GA digambarkan pada tabel dibawah ini. Nilai $k=3$ terpilih sebagai $k$ optimal. Besar kemungkinan terpilihnya $k$ optimal yang berbeda setiap kali melakukan eksekusi sistem, disebabkan oleh fase pembangkitan populasi secara acak, yang mana nilai fitness terbaik pada anggota populasi baru yang akan terpilih, namun pada penelitian ini model data set menghasilkan nilai $k$ yang konsisten di $k=3$. Nilai $k$ tersebut lebih kecil dari nilai $k$ yang dihasilkan oleh K-NN tanpa GA $(k=14)$. Nilai $k$ yang tinggi akan mengurangi efek noise pada klasifikasi, tetapi membuat batasan antara setiap klasifikasi 
Majalah Ilmiah Teknologi Elektro, Vol. 20, No.2, Jali-Desember 2021

DOI: https://doi.org/10.24843/MITE.2021.v20i02.P10

menjadi lebih kabur [20]. Batasan klasifikasi yang kabur mempengaruhi penilaian sistem dalam mengenali karakteristik data.

TABEL IV

PERSENTASE AKURASI K-NN BERBASIS GA

\begin{tabular}{|c|c|c|c|c|}
\hline \multirow{2}{*}{$\begin{array}{c}\text { Nilai } \\
\text { k }\end{array}$} & \multicolumn{3}{|c|}{ Persentase Akurasi } & \multirow{2}{*}{ Waktu } \\
\cline { 2 - 4 } & Exuberance & Contentment & Rata-rata & \\
\hline 3 & 89,19 & 89,19 & 89,19 & 0.0054 \\
\hline
\end{tabular}

K-NN tanpa GA mencapai akurasi tertinggi sebesar 87,84\% $(k=14)$, sedangkan K-NN dengan GA mencapai akurasi tertinggi sebesar 89,19\% $(k=3)$. Jika dibandingkan dengan nilai akurasi dari sistem klasifikasi K-NN konvensional, K$\mathrm{NN}$ berbasis GA terbukti lebih unggul. meskipun dengan selisih sebesar $1,35 \%$. Operasi optimasi melalui regenerasi individu terbaik terhadap sebuah populasi nilai $k$ oleh GA mempengaruhi hasil akurasi K-NN dalam melakukan klasifikasi. Sebab ketika masuk ke operasi klasifikasi oleh K$\mathrm{NN}$, data training yang sebelumnya diikutsertakan selama proses optimasi telah mengalami penyesuaian. Fitur-fitur yang tidak relevan disisihkan dalam upaya mencapai hasil yang diinginkan. Gambaran perbandingan tingkat akurasi hasil klasifikasi K-NN berbasis GA dengan K-NN tanpa GA dijelaskan pada Gambar 4.

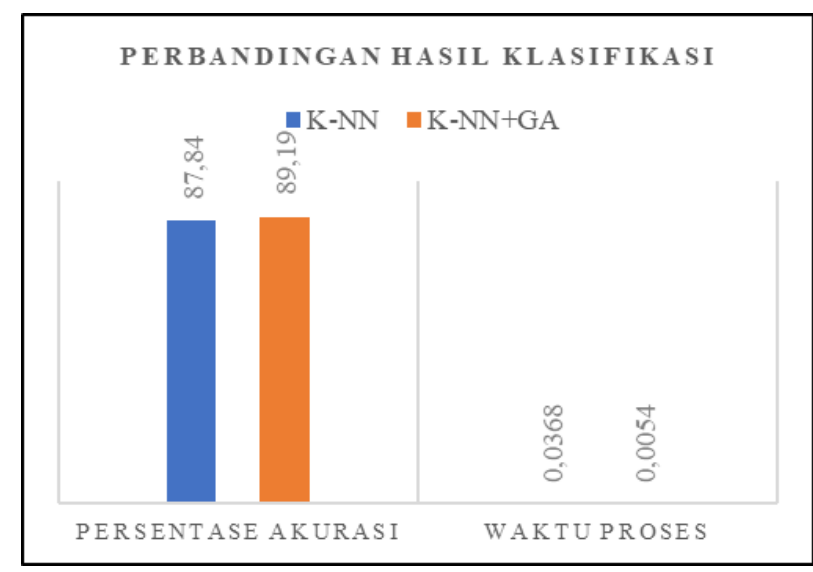

Gambar 4: Perbandingan hasil klasifikasi K-NN dan K-NN berbasis GA.

Proses pencarian nilai $k$ optimal oleh GA menambah tahapan yang perlu dikerjakan oleh sistem, sehingga waktu komputasinya akan lebih lama jika dibandingkan dengan waktu komputasi sistem tanpa GA. Demi mempertahankan kecepatan waktu proses algoritma klasifikasi, pada penelitian ini proses kerja GA diatur secara terpisah dan cukup dilakukan satu kali saja karena solusi yang dihasilkan dapat digunakan secara berkesinambungan oleh sejumlah data testing. Sebelumnya, GA telah mengeliminasi fitur-fitur tidak relevan pada data training, yang mengakibatkan proses

Tria Hikmah Fratiwi: Sistem Klasifikasi Musik Gamelan ... klasifikasi K-NN berbasis GA menjadi lebih cepat dibandingkan dengan klasifikasi K-NN tanpa GA.

K-NN dikenal sangat cepat dalam proses pelatihan dan klasifikasi data, karena pada prinsipnya K-NN memilih tetangga terdekat yang menggunakan parameter jarak yaitu euclidean distance yang cocok diterapkan dalam menentukan jarak terdekat antar dua data. Mengaplikasikan GA pada K$\mathrm{NN}$ dapat mempersingkat proses pencarian nilai $k$ optimal, dan meningkatkan keakuratan sistem dalam mendeteksi jenis suasana hati, serta memerlukan waktu komputasi yang lebih cepat dibandingkan dengan K-NN tanpa GA.

\section{KESIMPULAN}

$\mathrm{K}-\mathrm{NN}$ berbasis GA mencapai akurasi tertinggi sebesar $89,19 \%(k=3)$, sedangkan K-NN tanpa GA mencapai akurasi tertinggi sebesar $87,84 \%(k=14)$. Perbedaan tersebut terjadi karena data training pada sistem klasifikasi K-NN berbasis GA telah mengalami penyesuaian fitur selama proses optimasi oleh GA dalam upaya mencapai solusi yang diinginkan. Nilai $k$ optimal yang dihasilkan sistem klasifikasi $\mathrm{K}-\mathrm{NN}$ berbasis GA memiliki jangkauan tetangga yang lebih kecil jika dibandingkan dengan $k$ optimal K-NN tanpa GA, sehingga meminimalisir terjadinya klasifikasi yang samar. K-NN melakukan penghitungan tanpa bobot dalam setiap parameternya Sistem klasifikasi K-NN berbasis GA menghasilkan waktu pemrosesan tercepat 0,0054 detik, karena sebelumnya pada operasi GA telah dilakukan eliminasi fiturfitur yang tidak relevan pada data training. Penambahan operasi genetika oleh GA pada sistem klasifikasi K-NN berbasis GA tidak hanya membantu pencarian nilai $k$ optimal secara otomatis, melainkan juga meningkatkan persentase akurasi dan kecepatan waktu proses klasifikasi, sehingga dapat mencapai solusi yang optimal.

\section{REFERENSI}

[1] I. K. Donder, Esensi Bunyi Gamelan dalam Prosesi Ritual Hindu (Perspektif Filosofis-Teologis, Psikologis, Sosiologis, dan Sains). Surabaya: Paramita Surabaya, 2005.

[2] G. Harsemadi, M. Sudarma, and N. Pramaita, "Implementasi Algoritma K-Nearest Neighbor pada Perangkat Lunak Pengelompokan Musik untuk Menetukan Suasana Hati," Maj. Ilm. Teknol. Elektro, vol. 16, no. April, pp. 14-20, 2017.

[3] W. J. Shudiq, "Penerapan K-Nearest Neighbor Berbasis Algoritma Genetika untuk Klasifikasi Mutu Padi Organik," Pros. SNATIF Univ. Muria Kudus, pp. 121-126, 2017.

[4] H. Harafani, "Optimasi Algoritma Genetika Pada K-Nn Untuk Memprediksi Kecenderungan 'Blog Posting,"' J. Pendidik. Teknol. dan Kejuru., vol. 15, no. 1, pp. 20-29, 2018.

[5] P. Seni, S. Rupa, U. Gadjah, and M. Yogyakarta, "Kosmologis Tetabuhan dalam Upacara Ngaben,” vol. 15, no. 2, pp. 107-125, 2014.

[6] I. W. Suharta, "Pengembangan Gamelan Angklung Sebagai Pengiring Paket Seni Pertunjukan Wisata," Semin. Nas. Fak. Seni Pertunjuk., pp. 67-75, 2019

[7] I. M. Bandem, "Suasana Hati Gamelan Angklung Bali," 2018, Wawancara: Mei 2018, Jl. Sandat, Denpasar.

[8] F. Zhouyu, L. Guojia, T. Kaiming, and Z. Dengsheng, "A Survey of Audio-Based Music Classification and Annotation," IEEE Trans. Multimed., vol. 13, no. 2, pp. 303-319, 2011.

[9] A. Vidyawati and M. Hasanah, "Efektivitas Musik Klasik Untuk Menciptakan Suasana Hati Positif Pada Siswa Smp Semen Gresik," PSIKOSAINS (Jurnal Penelit. dan Pemikir. Psikologi), vol. 14, no. 1, p 71, 2019.

[10] X. Hu, "Music and mood: Where theory and reality meet," Proc. iConference, pp. 1-8, 2010.

[11] P. Ekkekakis, "The measurement of affect, mood, and emotion in p-ISSN:1693 - 2951; e-ISSN: 2503-2372 
exercise psychology," Meas. Sport Exerc. Psychol., pp. 321-332, 2012.

[12] R. Y. Sipasulta, A. S. M. L. St, and S. R. U. A. Sompie, "Simulasi Sistem Pengacak Sinyal Dengan Metode FFT (Fast Fourier Transform )," E-journal Tek. Elektro dan Komput., pp. 1-9, 2014.

[13] A. Lerch, An introduction to audio content analysis: Applications in signal processing and music informatics. 2012.

[14] F. D. Septria, N. Ibrahim, F. T. Elektro, and U. Telkom, "Klasifikasi Emosi Berdasarkan Sinyal Suara Manusia Menggunakan Metode KeyNearest Neighbor (K-NN)," e-Proceeding Eng., vol. 6, no. No. 2 Agustus, pp. 4130-4138, 2019.

[15] A. Mutoi Soregar, Amril; Puspabhuana, Data Mining Pengolahan Data Menjadi Informasi dengan RapidMiner. Surakarta: Kekata Publisher, 2017.

[16] S. Maulik, Ujjwal; Bandyopadhyay, "Genetic algorithm-based text clustering technique," Genet. algorithm-based Clust. Tech., vol. 4221 LNCS, pp. 779-782, 2000.

[17] I. M. (Fakultas T. U. U. Suwija Putra, "Penerapan Algoritma Genetika dan Implementasi dalam Matlab," 2018.

[18] P. dkk. Suwirmayanti, "Optimasi Pusat Cluster K-Prototype dengan Algoritma Genetika," Maj. Ilm. Teknol. Elektro, vol. 13, no. JuliDesember, pp. 16-23, 2014.

[19] A. Banjarsari, Mutiara Ayu; Budiman, Irwan; Farmandi, "Penerapan K-Optimal Pada Algoritma Knn Untuk Prediksi Kelulusan Tepat Waktu Mahasiswa Program Studi Ilmu Komputer Fmipa Unlam Berdasarkan Ip Sampai Dengan Semester 4," Klik - Kumpul. J. Ilmu Komput., vol. 2, no. 2, pp. 159-173, 2015.

[20] I. A. Angreni, S. A. Adisasmita, M. I. Ramli, and S. Hamid, "Pengaruh Nilai K Pada Metode K-Nearest Neighbor (Knn) Terhadap Tingkat Akurasi Identifikasi Kerusakan Jalan," Rekayasa Sipil, vol. 7, no. September, pp. 63-70, 2018. 